\title{
East Indian Sandalwood Oil Mouth Rinse
}

National Cancer Institute

\section{Source}

National Cancer Institute. East Indian Sandalwood Oil Mouth Rinse. NCI Thesaurus. Code C121509.

A mouth rinse containing $0.25 \%$ East Indian sandalwood oil, which is derived from the heartwood of Santalum album, a tree native to southern Asia, with potential antiinflammatory, anti-infective and anti-mucositis activities. East Indian sandalwood oil (EISO) is primarily comprised of the sesquiterpene alcohols alpha- and beta-santalol. Although the exact mechanisms of action through which EISO exerts its effects have yet to be fully elucidated, upon rinsing the oral cavity with the EISO mouth rinse, the active ing redients in the oil may inhibit the production of pro-inflammatory cytokines and chemokines, most likely through the inhibition of the activity of key inflammatory enzymes, including the cyclooxygenases. This prevents inflammation of the mucosal membranes and may prevent or decrease chemotherapy- and/or radiation-induced oral mucositis. 